\title{
Sleep Deprivation Triggers Inducible Nitric Oxide-Dependent Nitric Oxide Production in Wake-Active Basal Forebrain Neurons
}

\author{
Anna V. Kalinchuk, ${ }^{1}$ Robert W. McCarley, ${ }^{1}$ Tarja Porkka-Heiskanen, ${ }^{2}$ and Radhika Basheer ${ }^{1}$ \\ ${ }^{1}$ Laboratory of Neuroscience, Department of Psychiatry, Veterans Affairs Boston Healthcare System and Harvard Medical School, West Roxbury, \\ Massachusetts 02132, and 2Institute of Biomedicine, University of Helsinki, FIN-00014 Helsinki, Finland
}

\begin{abstract}
Sleep loss negatively impacts performance, mood, memory, and immune function, but the homeostatic factors that impel sleep after sleep loss are imperfectly understood. Pharmacological studies had implicated the basal forebrain (BF) inducible nitric oxide (NO) synthase (iNOS)-dependent NO as a key homeostatic factor, but its cellular source was obscure. To obtain direct evidence about the cellular source of iNOS-generated NO during sleep deprivation (SD), we used intracerebroventricular perfusion in rats of the cell membrane-permeable dye diaminofluorescein-2/diacetate (DAF-2/DA) that, once intracellular, bound NO and fluoresced. To circumvent the effects of neuronal NOS (nNOS), DAF-2/DA was perfused in the presence of an nNOS inhibitor. SD led to DAF-positive fluorescence only in the BF neurons, not glia. SD increased expression of iNOS, which colocalized with NO in neurons and, more specifically, in prolonged wakefulness-active neurons labeled by Fos. SD-induced iNOS expression in wakefulness-active neurons positively correlated with sleep pressure, as measured by the number of attempts to enter sleep. Importantly, SD did not induce Fos or iNOS in stress-responsive central amygdala and paraventricular hypothalamic neurons, nor did SD elevate corticosterone, suggesting that the SD protocol did not provoke iNOS expression through stress. We conclude that iNOS-produced neuronal NO is an important homeostatic factor promoting recovery sleep after SD.
\end{abstract}

\section{Introduction}

Sleep is a ubiquitous but imperfectly understood state. Among the candidate factors for its production is nitric oxide (NO), a gaseous neurotransmitter and intracellular signaling molecule synthesized by nitric oxide synthase (NOS) (Dzoljic and De Vries, 1994; Kapás et al., 1994a,b; Kapás and Krueger, 1996; Monti et al., 1999; Monti and Jantos, 2004). The neuronal form of NOS, nNOS, is constitutively expressed, and nNOS inhibition data suggest a role in sleep control (M. R. Dzoljic et al., 1996; E. Dzoljic et al., 1997; Williams et al., 1997; Burlet et al., 1999). Recently we have produced evidence (Kalinchuk et al., 2006a,b) for the role of $\mathrm{NO}$, acting in the basal forebrain (BF), as a key factor in sleep homeostatic regulation, defined as the biological mechanisms by which prolonged wakefulness or sleep deprivation (SD) leads to recovery sleep (Borbély, 1982). During SD, the BF concentration of nitrite and nitrate, an indirect measure of NO, doubled. Moreover both an NO scavenger and a nonselective NOS inhibitor abolished recovery sleep, whereas an NO donor increased non-

\footnotetext{
Received 0ct. 28, 2009; revised July 13, 2010; accepted July 23, 2010.

This work was supported by the Department of Veterans Affairs Medical Research Service Award (R.B.), a Sleep Research Society Foundation Christian Gillin Research Award (A.V.K.), and National Institute of Mental Health Grant NIMH39683 (R.W.M.). We thank Drs. Ritchie E. Brown, James T. McKenna, and Robert E. Strecker for stimulating discussions, Drs. Hemant Thatte and Dessislava Nikova for the help with microscopy, Farzana Pervin Nipa and Ajinkya Nene for excellent technical assistance and the help with immunohistochemistry, and Peter Hirsch, Dewayne Williams, and Diane Ghera for providing exceptional animal care.

Correspondence should be addressed to Anna V. Kalinchuk or Radhika Basheer, Laboratory of Neuroscience, Department of Psychiatry, Harvard Medical School/Boston Veterans Affairs Healthcare System, 1400 V.F.W. Parkway, West Roxbury, MA 02132. E-mail: anna_kalinchuk@hms.harvard.edu; radhika_basheer@hms.harvard.edu. DOI:10.1523/JNEUROSCI.0014-10.2010

Copyright $\odot 2010$ the authors $\quad$ 0270-6474/10/3013254-11\$15.00/0
}

rapid eye movement (NREM) sleep (Kalinchuk et al., 2006a). Our data further indicated that SD-induced NO in the BF was synthesized by inducible NOS (iNOS), because iNOS inhibition prevented recovery NREM sleep after SD, whereas inhibition of neuronal nNOS did not (Kalinchuk et al., 2006b).

Inhibiting iNOS also prevented an adenosine increase in the $\mathrm{BF}$ during $\mathrm{SD}$, suggesting that iNOS-dependent $\mathrm{NO}$ acts to produce adenosine. The discovery of BF iNOS effects on adenosine was of interest in view of data indicating that more than one mechanism is likely involved in sleep homeostasis. We and others have produced data indicating that adenosine is an important homeostatic sleep factor and that the BF wakefulness center is an important site of its action (Porkka-Heiskanen et al., 1997, 2000; Basheer et al., 2004; Murillo-Rodriguez et al., 2004; McCarley, 2007). Data suggest that extracellular adenosine in the BF gradually increases during prolonged wakefulness and acts to inhibit the BF wakefulness-active neurons (Thakkar et al., 2003a; Arrigoni et al., 2006), thereby allowing the onset of sleep. Different homeostatic mechanisms appear to be called into play according to the severity of sleep loss. For example, with prolonged exposure to elevated adenosine levels, there is a positive feedback of adenosine on the number of active $A_{1}$ receptors, with the number of active receptors increasing (Basheer et al., 2007; Elmenhorst et al., 2007, 2009). We thus think that the term "homeostatic cascade" is appropriate for this aspect of sleep homeostasis.

Although these data suggested that NO was a key homeostatic cascade component, critical issues remained. It remained to be shown in which brain cells NO was produced and to demonstrate a direct link between iNOS induction and NO production within 
A
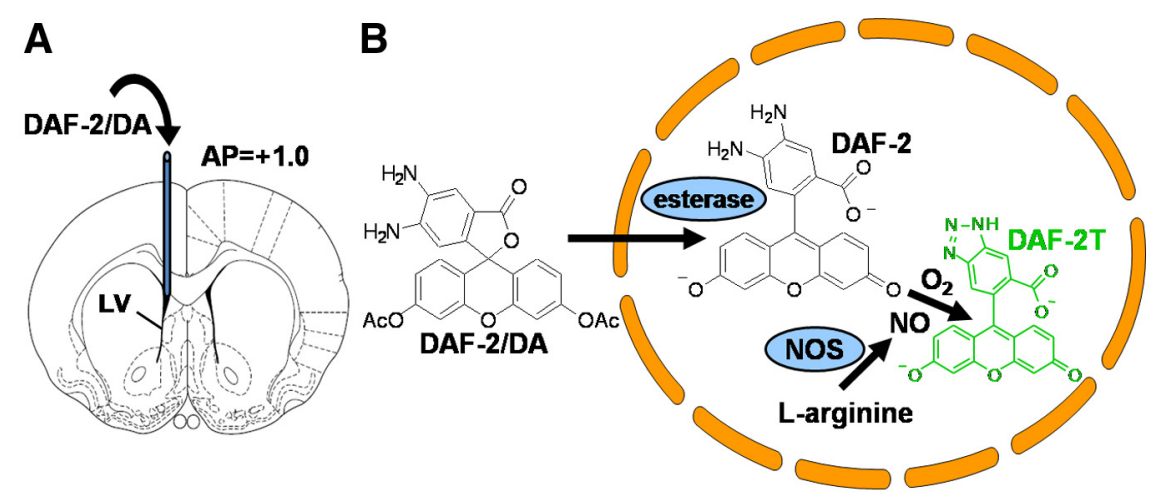

C

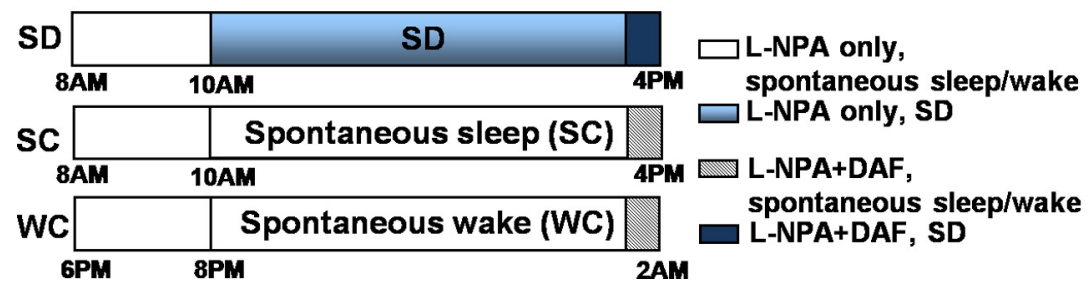

Figure 1. Labeling of N0-producing cells in vivo using DAF-2/DA. A, Location of chronically implanted microdialysis guide cannula for intracerebroventricular infusion of DAF-2/DA in the rat brain. LV, Lateral ventricle. $B$, Schematic of DAF-2/DA transformation into DAF-2 triazole (DAF-2T, DAF). Membrane-permeable DAF-2/DA is hydrolyzed by cytosolic esterases, releasing membrane-impermeable DAF-2, which is nonfluorescent. In the presence of N0 and ${ }_{2}$ it forms the highly fluorescent DAF-2T (DAF; for more details, see Materials and Methods). C, Experimental paradigm for animals receiving L-NPA and DAF-2/DA. The SD group had $6 \mathrm{~h}$ SD, 10:00 A.M. to 4:00 P.M. Comparison groups with the SD group were an SC group, which allowed $6 \mathrm{~h}$ spontaneous sleep-wake from 10:00 A.M. to 4:00 P.M. (inactive period, mainly sleep, $<20 \%$ of wake) and a WC group, which allowed $6 \mathrm{~h}$ spontaneous wake-sleep from 8:00 P.M. to 2:00 A.M. (active period, mainly wake, $<20 \%$ of sleep). All groups had $2 \mathrm{~h}$ of pretreatment with L-NPA before the $6 \mathrm{~h}$ experimental period, and all groups had DAF-2/DA perfusion for the last $0.5 \mathrm{~h}$ of the experimental period. Animals participating in the experiments of the second type were used for iNOS fluorescence intensity analysis/cell counting, and double labeling of iNOS staining with GFAP, NeuN, and Fos had the same sleep-wake protocols but no L-NPA or DAF perfusion.

specific cells. The concept of SD-induced induction of iNOS was particularly intriguing because iNOS has been generally considered to be virtually absent in the adult healthy brain and to be induced only by pathological stimuli (Zhan et al., 2005; Calabrese et al., 2007). Thus, clear evidence about the cellular source of iNOS induction during SD would have general implications for our understanding of the role of iNOS in nonpathological conditions. In this report, we describe the use of a novel assay of in vivo intracellular fluorescent $\mathrm{NO}$ staining using 4,5-diaminofluorescein-2/diacetate (DAF-2/DA), a cell-membrane-permeable dye that binds intracellular NO (Kojima et al., 1998a,b). Using in vivo NO staining combined with iNOS immunohistochemistry, we present direct evidence that iNOS-dependent NO production occurs in wakefulness-active BF neurons and that the extent of this production is positively correlated with the degree of homeostatic sleep pressure.

\section{Materials and Methods}

Animals and surgical procedures. Experiments were performed on male Wistar rats (300-400 g; Charles River Laboratories). Animals were housed in a room with constant temperature $\left(23.5-24^{\circ} \mathrm{C}\right)$ and $12 \mathrm{~h} \mathrm{light/}$ dark cycle (lights on at 8:00 A.M.). Water and food were provided ad libitum. Starting $5 \mathrm{~d}$ before the surgery, animals were habituated to experimenters by daily $10 \mathrm{~min}$ training sessions that included touching and removal from the cages. During surgery under general anesthesia (ketamine at $7.5 \mathrm{mg} / 100 \mathrm{~g}$ body weight, xylazine at $0.38 \mathrm{mg} / 100 \mathrm{~g}$, and acepromazine at $0.075 \mathrm{mg} / 100 \mathrm{~g}$, i.m.), rats were implanted with electroencephalogram (EEG) and electromyogram (EMG) electrodes. EEG electrodes (stainless steel screws) were implanted epidurally over the frontal [primary motor: anteroposterior (AP), $+2.0 \mathrm{~mm}$; mediolateral (ML), $2.0 \mathrm{~mm}]$ and parietal (retrosplenial: AP, $-4.0 \mathrm{~mm}$; ML, 1.0 $\mathrm{mm}$ ) cortices. EMG recording electrodes (silver wires covered with Teflon) were implanted into neck muscles. In animals used for the infusion of DAF-2/DA (first group of experiments, see below, Experimental paradigm), unilateral guide cannulae (CMA/11 Guide; CMA/Microdialysis) were implanted, targeting the lateral ventricles [AP, + $1 \mathrm{~mm}$; ML, + $1 \mathrm{~mm}$; ventral $(\mathrm{V}), 4.5$ $\mathrm{mm}$ (Paxinos and Watson, 1998)] (Fig. 1A). In experiments in which DAF-2/DAF was not infused (experiments of the second type, see below, Experimental paradigm), rats were implanted only with electrodes for EEG/EMG recording.

In our pilot experiments, we used unilateral intra-BF injections of glutamate (supplemental Fig. S1, available at www.jneurosci.org as supplemental material). They were performed in anesthetized animals under stereotaxic control using the following coordinates: $\mathrm{AP},-0.3 \mathrm{~mm}$; $\mathrm{ML},+1.5 \mathrm{~mm}$; V, $8.5 \mathrm{~mm}$ (Paxinos and Watson, 1998).

To confirm the specificity of iNOS antibody used in our study, we performed a short experiment ( $n=2$ /genotype) using iNOS knock-out (KO) mice and corresponding wild-type mice (iNOS WT) (male mice, 25-30 g, C57BL/6J; The Jackson Laboratory). Mice were kept at the same conditions as described above for rats. During surgery, mice were implanted with EEG/EMG recording electrodes and microdialysis guide cannulae (CMA/7 Guide; CMA/Microdialysis) targeting the lateral ventricles $[\mathrm{AP},+0.02 \mathrm{~mm}$; ML, $+1.5 \mathrm{~mm}$; V, $3 \mathrm{~mm}$ (Franklin and Paxinos, 2007)].

All surgical and experimental protocols were in accordance with the American Association for Accreditation of Laboratory Animal Care policy on care and use of laboratory animals. Every effort was made to minimize animal suffering and to reduce the number of animals used.

Recovery and adaptation. After surgery, the rats and mice were housed in individual cages and were allowed 1 week of recovery from surgery before procedures. Beginning $3 \mathrm{~d}$ after surgery, daily $10 \mathrm{~min}$ training sessions were resumed. Habituation was regarded as complete when there were no reactions of fear or aggression when the experimenter approached the cage and touched the animals.

After 1 week of recovery period, animals were connected to EEG/EMG recording leads for adaptation for $4 \mathrm{~d}$. On the last day of adaptation, EEG/EMG were continuously recorded starting at 8:00 A.M. for at least $24 \mathrm{~h}$ to monitor the stabilization of EEG and sleep-waking cycle. All efforts were made to achieve maximal adaptation of animals to the experimental conditions and minimize possible stress related to novelty of manipulations during experiments.

Sleep deprivation paradigm. In all experiments, SD for 6 h (10:00 A.M. to 4:00 P.M.) was done using the gentle handling protocol (Franken et al., 1991), which included presentation of new objects into the cages and a gentle touching of the animals by a brush or by hands when the rats were attempting to sleep. Attempts to sleep were identified by the onset of behaviors typical of sleep such as cornering, curling, eye closing, etc. and by the appearance of the first slow waves in the EEG. The numbers of sleep attempts were used as a measure of sleep pressure and were averaged for each rat over last $2 \mathrm{~h}$ of SD. EEG/EMG recordings were continuously performed during SD to monitor the effectiveness of the SD protocol. Only animals with $<15 \%$ of sleep during the $6 \mathrm{~h}$ of SD were included in the analysis. Changes in the SD group were compared with changes in the two control groups: sleeping (SC) and waking (WC) (see below, Experimental paradigm). Animals in the control groups were also 
gently handled (touched with brush or hands) for 3-5 min during episodes of spontaneous wakefulness. In this way, the possibility that SDinduced changes were evoked by the sensory stimulation associated with gentle handling procedure rather than prolongation of wakefulness was minimized.

Detection of NO production in the BF using the fluorescent dye DAF-2/ $D A$. We used DAF-2/DA (Calbiochem) as a fluorescent indicator of NO for direct measurements of intracellular NO (Kojima et al., 1998a,b). The diacetate salt DAF-2/DA is taken up by cells, in which it is esterified by intracellular esterases to form the relatively nonfluorescent compound DAF-2, which, in the presence of $\mathrm{NO}$ and $\mathrm{O}_{2}$, is converted to the highly fluorescent triazolofluorescein DAF-2T (DAF) (Fig. $1 B$ ) with excitation/ emission at 495/515 nm, respectively (Kojima et al., 1998a,b). Because of the extremely high sensitivity $(2-5 \mathrm{nM} \mathrm{NO})$ and the direct correlation of fluorescence intensity with the amount of NO, DAF-2/DA permits the direct visualization and quantitative analysis of $\mathrm{NO}$ production at the single-cell level. Also, it has been shown that the reaction between DAF-2 and NO is irreversible (Kojima et al., 1998a); therefore, the accumulated level of DAF-2 fluorescence reflects the total amount of cellular NO production within the period.

In our novel use of DAF labeling of $\mathrm{NO}$-producing cells in vivo during $\mathrm{SD}$, we administered DAF-2/DA intracerebroventricularly using microdialysis (Fig. 1A). Pilot studies showed that DAF-2/DA administered intracerebroventricularly reached the BF; these studies injected glutamate (10 mM), a known activator of NOS (Bredt and Snyder, 1989), into the BF of rats, followed by intracerebroventricular infusion of DAF-2/ DA. This treatment produced abundant DAF-positive $\left(\mathrm{DAF}^{+}\right)$staining in the infused BF side (supplemental Materials, available at www. jneurosci.org as supplemental material). Other pilot studies determined the minimal effective dose of DAF-2/DA to be $5 \mu \mathrm{M}$ and best timing of infusion to be $30 \mathrm{~min}$ before the animals were killed (data not shown).

In all experiments, DAF-2/DA was administered via a microdialysis probe that was inserted into a guide cannula $20 \mathrm{~h}$ before the experiment; the microdialysis pump had a flow rate of $1 \mu \mathrm{l} / \mathrm{min}$. DAF-2/DA was dissolved in a mixture of artificial CSF (aCSF) (Harvard Apparatus) and HBSS (Sigma-Aldrich) (1:1) to produce a within-probe concentration of $5 \mu \mathrm{M}$. As indicated by the specifications of the manufacturer and our previous experience (Porkka-Heiskanen et al., 1997), the CMA probe delivers an external concentration of $\sim 10 \%$ of the within-probe concentration; this indicates a $\sim 0.5 \mu \mathrm{M}$ concentration in the tissue outside the probe.

Our initial experiments showed that the basal level of NO in the BF, likely from constitutive NOS activity, prevented identification of SDinduced NO (see Results). We thus inhibited nNOS activity using the selective inhibitor $N^{\omega}$-propyl-L-arginine (L-NPA) (Tocris Bioscience), delivered at a $100 \mu \mathrm{m}$ concentration in an aCSF + HBSS solution through the same probe as DAF-2/DA. This concentration of L-NPA in the infused solution released $\sim 10 \mu \mathrm{M} \mathrm{L}-\mathrm{NPA}$ in the tissue surrounding the probe; at this concentration, L-NPA selectively inhibits nNOS and endothelial NOS (eNOS) but does not affect iNOS $\left(K_{\mathrm{i}}=57 \mathrm{~nm}, 8500 \mathrm{~nm}\right.$, and $1.8 \times 10^{5} \mathrm{~nm}$ for nNOS, eNOS, and iNOS, respectively) (Zhang et al., 1997).

Immunohistochemistry. At the end of experiments, animals designated for immunohistochemistry and fluorescence intensity analysis/cell counting were deeply sedated with $\mathrm{CO}_{2}$ and transcardially perfused with $4 \%$ formaldehyde. Brains were removed from the skull, fixed in $4 \%$ formaldehyde overnight, cryoprotected in 30\% sucrose, and frozen. Coronal $30 \mu \mathrm{m}$ sections were cut using a cryostat. Consecutive sections were first treated with $3 \%$ Triton $\mathrm{X}-100$ for $1 \mathrm{~h}$ at room temperature, then blocked in $0.3 \%$ donkey serum for $1 \mathrm{~h}$, and incubated overnight at $4{ }^{\circ} \mathrm{C}$ with one of the primary antibodies: anti-iNOS (mouse monoclonal, 1:15,000; Sigma-Aldrich), anti-nNOS (rabbit polyclonal, 1:200; BD Biosciences), anti-neuron-specific nuclear protein (NeuN) (neuronal marker; mouse monoclonal, 1:500; Millipore Bioscience Research Reagents), or anti-glial fibrillary acidic protein (GFAP) (glial marker; mouse monoclonal, 1:500; Sigma-Aldrich). On the following day, sections were treated for $1 \mathrm{~h}$ with anti-mouse or anti-rabbit fluorescent secondary antibodies with green, red, or blue fluorescence, respectively (1:500, Alexa Fluor 488, 568, or 647; Invitrogen). Subsequently, sections assigned for double labeling were blocked in $0.3 \%$ donkey or mouse serum and incubated overnight at $4^{\circ} \mathrm{C}$ with different primary antibody, followed by incubation with a corresponding secondary antibody of different color and mounted with Fluoromount-G (Southern Biotechnology Associates). For double labeling of iNOS and Fos, sections were blocked in 3\% Triton X-100 for $1 \mathrm{~h}$ at room temperature and $0.3 \%$ donkey serum and incubated overnight with anti-Fos primary antibody (goat polyclonal, 1:200; Santa Cruz Biotechnology) at $4^{\circ} \mathrm{C}$. The next day sections were incubated for $1 \mathrm{~h}$ with biotinylated donkey anti-goat IgG (1:400; Millipore Bioscience Research Reagents) and avidin-biotin complex solution for $1 \mathrm{~h}$ (Vectarin ABC kit; Vector Laboratories) and developed with diaminobenzidine (DAB peroxidase substrate kit; Vector Laboratories) in the presence of nickel to produce black reaction product. Fos-labeled sections were blocked with $0.3 \%$ donkey serum and treated overnight with anti-iNOS primary antibody at $4^{\circ} \mathrm{C}$. On the next day, they were incubated with biotinylated donkey anti-mouse IgG for $1 \mathrm{~h}$ (1:400; Millipore Bioscience Research Reagents), for $1 \mathrm{~h}$ with $\mathrm{ABC}$, developed with $\mathrm{DAB}$ to produce a brown reaction product, and mounted using Permount mounting medium (Thermo Fisher Scientific). The specificity of iNOS antibody was tested using iNOS KO mice. Immunostaining was always performed simultaneously on pairs of sections from SD and control experimental groups.

Quantitative analysis of fluorescence intensity and cell counting. To quantify the SD-induced changes in $\mathrm{NO}$ and iNOS production in the $\mathrm{BF}$, we compared the fluorescence intensity of individual $\mathrm{DAF}^{+}$or iNOS ${ }^{+}$ cells and the numbers of positively stained DAF, iNOS, and DAF/iNOS cells in the SD, SC, and WC groups. Fluorescence microscopy was performed using the Olympus BX51 microscope, and quantitative analysis was performed using MetaMorph Software (version 6.1; Molecular Devices). Images from the $\mathrm{BF}$ area in each animal were collected at $20 \times$ magnification using blue and/or red filters. Five comparable coronal sections from different rats were matched using anatomical landmarks and bregma coordinates [AP levels: $+0.48,+0.2,-0.26,-0.4$, and -0.8 $\mathrm{mm}$ (Paxinos and Watson, 1998)], and the area of the BF nuclei [horizontal limb of diagonal band (HDB), substantia innominata (SI), and magnocellular preoptic area (MCPO)] was outlined in each section.

For the analysis of fluorescence intensity of individual cells stained for DAF or iNOS, each cell was outlined and its fluorescence intensity was defined. The average fluorescence intensity of all cells in each section was normalized against the background by moving the outline of a cell to the neighboring area on tissue in which no fluorescent cell body was detected. These values from five sections were averaged to form the grand average for each rat.

For counting of $\mathrm{DAF}^{+}, \mathrm{iNOS}^{+}$, and $\mathrm{DAF}^{+} / \mathrm{iNOS}^{+}$cells, two images of each of five sections per rat stained for both iNOS and DAF were taken. For counting of double-labeled cells, two images were merged using MetaMorph Software. Only cells that had intensity at least 1.5 times greater than background were counted. Counts from five sections were summarized to yield a total number of cells for each rat ( $n$ values of rats are specified for each experiment in Results).

For counting iNOS ${ }^{+} / \mathrm{Fos}^{+}$or Fos ${ }^{+}$cells, images were collected at $20 \times$ using a light microscope. In total, the following images were used for counting: for the $\mathrm{BF}$ area, images of five sections per rat (the same AP levels as described above); for the paraventricular hypothalamus (PVH), images of three sections per rat [AP levels: $-0.92,-1.40$, and $-1.88 \mathrm{~mm}$ (Paxinos and Watson, 1998)]; and for the central amygdala (CeA), images of five sections per rat (AP levels: $-1.60,-1.88,-2.30,-2.80$, and $-3.14 \mathrm{~mm}$ ). $\mathrm{Fos}^{+}$cells were identified by the presence of a black nucleus, and NOS $^{+}$cells were defined by the presence of brown cytoplasm.

EEG recording and analysis. EEG/EMG recordings were used to confirm the effectiveness of SD and sleep-waking pattern of controls. In SC group, only animals that had $<20 \%$ of wake within the $6 \mathrm{~h}$ experimental period were included in the final analysis, and only animals that had $<20 \%$ of sleep within the $6 \mathrm{~h}$ experiment were used for the WC group data.

The EEG/EMG polygraphic data were recorded by the Grass 15LT physiodata amplifier system. The signals were captured by Gamma (version 4.2) acquisition software (Grass-Telefactor) using a sampling rate of $256 \mathrm{~Hz}$. EEG recordings was visually scored at $10 \mathrm{~s}$ epochs using rodent sleep stager software (RSS version 3; Grass-Telefactor) according to previously described criteria for wakefulness, NREM, and REM sleep (Basheer et al., 1999; Kalinchuk et al., 2006a,b). 
A

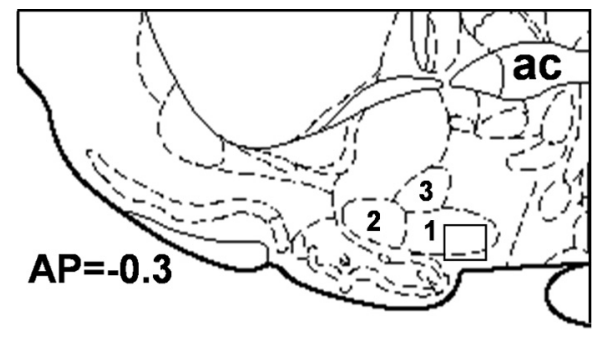

B
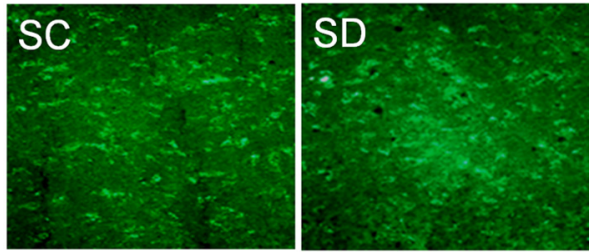

C
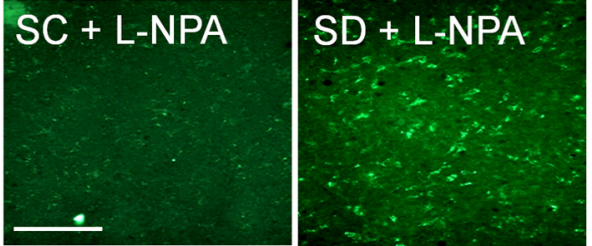

Figure 2. Visualization of SD-induced NO production in the BF after nNOS inhibition. $\boldsymbol{A}$, The rectangle indicates the position of the area shown in photomicrographs in $\boldsymbol{B}$ and $\boldsymbol{C}$ ac, Anterior commissure. 1, 2, and 3 indicate the BF nuclei: 1, HDB; 2, MCPO; 3 , SI. $\boldsymbol{B}$, Histology without nNOS inhibition. Note that the background $\mathrm{DAF}^{+}$fluorescence from the basal nNOS activity does not allow detection of differences in NO production between SC and SD. C, Histology with nNOS inhibition by the selective inhibitor L-NPA. Note the clear visualization of increased NO production in SD compared with SC. Scale bar, $100 \mu \mathrm{m}$.
Corticosterone measurements. To compare the stress level in the SD and control animals, we measured plasma corticosterone using the Enzyme Immunoassay kit (Assay Designs). Blood was very quickly (1-2 min) collected by intracardiac puncture before the start of transcardial perfusion. A total of $2 \mathrm{ml}$ of blood was placed into prechilled tubes containing $200 \mu \mathrm{l}$ of disodium EDTA ( $20 \mathrm{ml} / \mathrm{mg}$; Sigma-Aldrich) and centrifuged at $2000 \mathrm{rpm}$ for $10 \mathrm{~min}$ at room temperature. Plasma was collected and stored at $-80^{\circ} \mathrm{C}$ until assayed. Corticosterone was measured from samples diluted 1:50 according to the instructions of the manufacturer (the sensitivity of the assay is $<27 \mathrm{pg} / \mathrm{ml}$ ).

Experimental paradigm. Two types of experiments were performed. (1) The first type used infusion of DAF-2/DA and L-NPA and double labeling of DAF staining with iNOS, nNOS, GFAP, and NeuN. (2) The second type did not have pharmacological treatment with L-NPA or DAF-2/DA and was used for iNOS fluorescence intensity analysis/cell counting and double labeling of iNOS staining with GFAP, NeuN, and Fos.

All rats participating in the first type of experiments were assigned to one of three groups: SD and two control groups, SC and WC (see sketch of experimental paradigm in Fig. 1C). All experiments lasted $6 \mathrm{~h}$ plus pretreatment with L-NPA, which began $2 \mathrm{~h}$ before and continued throughout the 6 experimental hours (Fig. 1C). As noted above, treatment with L-NPA was required to block constitutive NOS activity.

Rats in the SD group were sleep deprived between 10:00 A.M. and 4:00 P.M. Pretreatment with L-NPA started at 8:00 A.M. and continued throughout SD; between 3:30 P.M. and 4:00 P.M., animals received a mixture of L-NPA and DAF-2/DA. Animals in SC group received similar pharmacological treatment, but they were allowed spontaneous sleepwake between 8:00 A.M. and 4:00 P.M. Animals in WC group were killed at 2:00 A.M., after $6 \mathrm{~h}$ of spontaneous wake-sleep, and similar treatment with L-NPA and, during the last $30 \mathrm{~min}$, L-NPA + DAF-2/DA. Immediately after DAF-2/DA delivery, animals were transcardially perfused with $4 \%$ formaldehyde, and brains were collected for further investigation. A similar experiment was also performed using the iNOS KO mice and their corresponding WT mice. This experiment was performed to confirm the specificity of iNOS antibody.

Rats participating in the second type of experiments were similarly divided into three groups (SD, SC, and WC) and followed the same sleep-wake schedule as described for the first type of experiments, but they did not receive any pharmacological treatment.

Statistics. Data are expressed as mean \pm SEM. Statistical analysis was performed using SigmaStat 3.0 Statistical software (SPSS Inc.). To evaluate the statistical significance of the differences among the three groups (SD, SC, and WC), we used the nonparametric KruskalWallis one-way ANOVA on ranks, followed by post hoc Mann-Whitney rank sum tests. To evaluate the statistical significance of the difference when only two groups were compared, such as the numbers of DAF ${ }^{+}, \mathrm{iNOS}^{+}, \mathrm{Fos}^{+}$ and double-labeled cells in SD and SC, we used the Mann-Whitney rank sum test. The association between the numbers of $\mathrm{iNOS}^{+} / \mathrm{Fos}^{+}$ cells and the attempts to enter sleep was measured using Pearson's correlation coefficient.

\section{Results}

DAF detection shows increased SD-dependent NO production in the basal forebrain in the presence of an nNOS inhibitor

We first determined that our in vivo method of staining of NO-producing cells with intracerebroventricular application of DAF-2/DA (Fig. $1 A, B$ ) reliably labeled cells in the $\mathrm{BF}$ area by stimulating local
Figure 3. Analysis of fluorescence intensity of DAF and iNOS staining in the BF after SD and in controls (SC and WC). Average intensity of $\mathrm{DAF}^{+}$and iNOS ${ }^{+}$cells from five coronal sections throughout the BF (AP, $+0.48,+0.2,-0.26$, -0.4 , and $-0.8 \mathrm{~mm}$ ) was measured using MetaMorph Software. $A$, Intensity of fluorescent $\mathrm{DAF}^{+}$staining (green) in the $\mathrm{BF}$ after SD is approximately fourfold higher compared with SC and WC. $\boldsymbol{B}$, Intensity of fluorescent iNOS ${ }^{+}$staining (red) in the BF after SD is approximately sevenfold higher compared with SC and WC. Note that, for both DAF and iNOS staining, there was no difference between SC and WC, thus indicating that increased NO/iNOS production in the BF occurs af ter prolonged waking but not after spontaneous waking. ${ }^{*} p<0.05$, SD significantly different from WC and SC. Scale bar $50 \mu \mathrm{m}$.

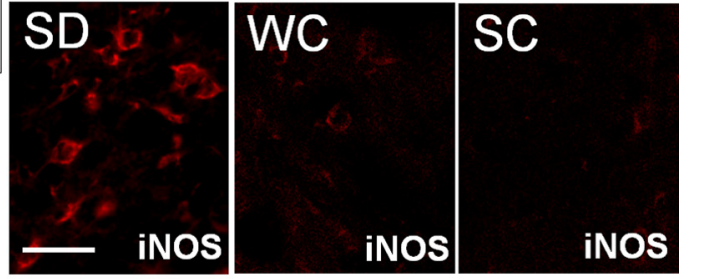


NO production using targeted intra-BF injection of glutamate (10 mM), a known NOS activator (Bredt and Snyder, 1989) (supplemental Fig. S1, available at www. jneurosci.org as supplemental material). Next, we demonstrated that this method was sensitive enough to detect SDinduced changes in NO in the BF. Our $6 \mathrm{~h}$ experimental protocol for detecting the state dependence of NO production compared three groups of rats: SD, SC, and, to contrast SD-induced wakefulness with spontaneous wakefulness, a WC group. All groups had DAF-2/DA infusion during the last half hour before decapitation (Fig. 1C). Initial experiments showed that perfusion of the selective nNOS inhibitor L-NPA $(100 \mu \mathrm{M})$ was needed to suppress the basal constitutive NOS activity that obscured the effects of SD (Fig. 2). In the present study, intracerebroventricular administration of L-NPA induced a statistically significant $10 \%$ decrease in NREM sleep (data not shown), similar to that reported previously $(15 \%$ decrease in NREM sleep) (Kalinchuk et al., 2006b).

To quantify the between-state difference in NO production, we first calculated the average fluorescence intensity of $\mathrm{DAF}^{+}$staining in the presence of L-NPA in three experimental groups $(n=4$ rats per group). There was an overall difference between groups (Kruskal-Wallis one-way ANOVA on ranks, $H_{(2)}=8.000$, $p=0.005)$, and SD produced an approximately fourfold increase in $\mathrm{DAF}^{+}$fluorescence intensity in the $\mathrm{BF}$ compared with the SC and WC groups ( post hoc Mann-Whitney rank sum comparison, $\mathrm{SD}>\mathrm{SC}$ and $\mathrm{SD}>\mathrm{WC}$, both $t=10.000, p=$ $0.029)$. There was no significant difference between the SC and WC groups ( post hoc Mann-Whitney rank sum comparison, $t=$ 14.000, $p=0.343$ ), thus showing that the increase in NO was attributable to the prolonged wakefulness during SD but not to spontaneous wakefulness (Fig. 3A).

Immunolabeling shows SD-dependent iNOS induction in the basal forebrain

Our initial report used Western blot measurement of iNOS to show that SD leads to iNOS induction in the BF (Kalinchuk et al., 2006b). Here we tested whether this finding could be confirmed by iNOS immunohistochemistry and by comparing the fluorescence intensity of $\mathrm{iNOS}^{+}$staining in the BF cells in three groups of rats (SD, SC, and WC, $n=4$ per group). Rats used in this experiment were not treated with DAF-2/DA and L-NPA. The specificity of the iNOS antibody used for immunolabeling was confirmed in iNOS KO mice.

Among the three experimental groups, only in the SD group did the iNOS antibody detect the presence of clear iNOS ${ }^{+}$staining in the BF (Fig. $3 B)$. Both large $(\sim 25 \mu \mathrm{m})$ and small $(\sim 10 \mu \mathrm{m})$ round and spindle-shaped cells were labeled. In the SC and WC groups, only weak $\mathrm{iNOS}^{+}$staining was detected, mostly in small cells. A quantitative analysis of NOS $^{+}$fluorescence intensity revealed an overall difference in treatments (Kruskal-Wallis one- way ANOVA on ranks, $\left.H_{(2)}=8.000, p=0.005\right)$ and that SD induced an approximately sixfold increase in iNOS level compared with WC (post hoc Mann-Whitney rank sum comparison, $t=$ $10.000, p=0.029)$ and an approximately eightfold increase compared with SC ( post hoc Mann-Whitney rank sum comparison, $t=10.000, p=0.029)$. As was seen in the case of $\mathrm{DAF}^{+}$staining, there was no significant difference between the SC and WC groups ( post hoc Mann-Whitney rank sum comparison, $t=$ 14.000, $p=0.343$ ) (Fig. 3B).

\section{Double labeling shows that SD-dependent NO production} detected by DAF is colocalized with iNOS but not with nNOS Next we evaluated whether cellular NO production during SD detected by DAF was attributable to iNOS induction rather than to residual constitutive NOS activity resulting from incomplete inhibition of nNOS after intracerebroventricular L-NPA infusion. Consecutive BF sections from two groups of rats treated with L-NPA + DAF-2/DA (SD and SC, $n=4$ per group) were subjected to immunohistochemistry using antibodies specific for nNOS and iNOS. As is apparent from visual inspection of Figure 4 , the majority of $\mathrm{DAF}^{+}$cells in the SD group were iNOS ${ }^{+}$, whereas the isolated, weak $\mathrm{DAF}^{+}$staining in SC did not colocalize with iNOS. In the SD group, only a few of $\mathrm{DAF}^{+}$cells were $\mathrm{nNOS}^{+}$, whereas in SC group almost all $\mathrm{DAF}^{+}$cells were $\mathrm{nNOS}^{+}$.

For a quantitative analysis of iNOS-dependent NO production, $\mathrm{DAF}^{+}, \mathrm{iNOS}^{+}$, and $\mathrm{DAF}^{+} / \mathrm{iNOS}^{+}$cells in the SD and SC 
A
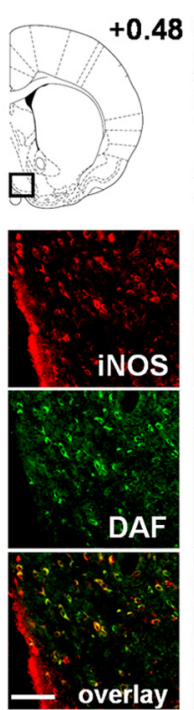
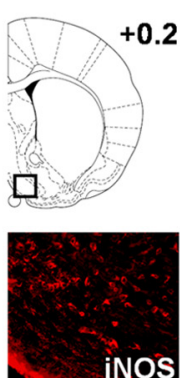

inOS
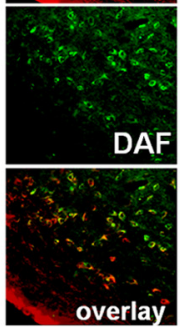
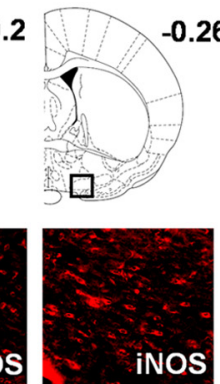

iNOS

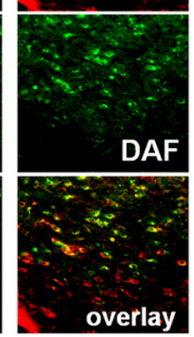

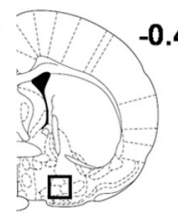

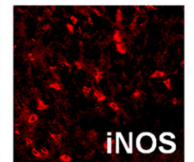

iNOS

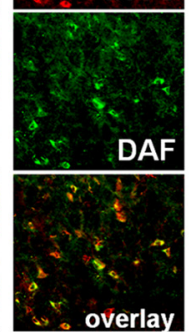

0.4
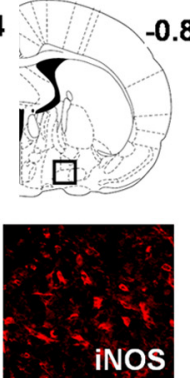

iNOS

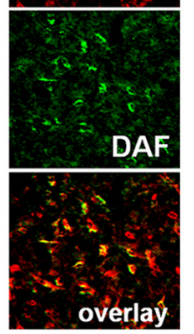

B

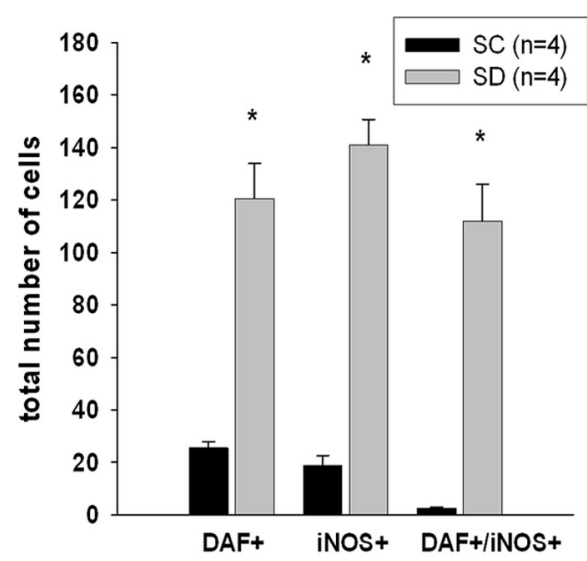

Figure 5. Analysis of iNOS-dependent NO production in the BF after SD.A, DAF ${ }^{+}$, iNOS ${ }^{+}$, and iNOS ${ }^{+} / \mathrm{DAF}^{+}$cells were counted in five sections collected throughout the BF. The top row shows the AP levels of sections taken for analysis (Paxinos and Watson, 1998). Squares indicate the areas of the photomicrographs in the bottom rows. The bottom rows show significant colocalization of $\mathrm{iNOS}^{+}$(red) and DAF ${ }^{+}$(green) stains throughout the entire BF area in this representative rat from SD group. B, Quantitative analysis of numbers of DAF ${ }^{+}$, iNOS ${ }^{+}$, and DAF ${ }^{+} / \mathrm{iNOS}^{+}{ }^{+}$cells in the BF in SD and SC groups. SD induced significant increases in numbers of DAF ${ }^{+}$and iNOS ${ }^{+}$cells in the BF. The overwhelming majority of DAF ${ }^{+}$cells in SD were also iNOS ${ }^{+}\left(\right.$labeled as DAF $\left.{ }^{+} / \mathrm{iNOS}^{+}\right)$. In sections from a representative sleeping control rat, only few DAF ${ }^{+}$cells were iNOS ${ }^{+}$. Scale bar, $100 \mu \mathrm{m} .{ }^{*} p<0.05$, SD significantly different from SC.

groups were counted in five sections taken through the BF. An overwhelming majority of $\mathrm{DAF}^{+}$cells (Fig. $5 A$ ) in the SD group were $\mathrm{iNOS}^{+}\left(92.2 \pm 2 \%\right.$ of all $\mathrm{DAF}^{+}$cells $)$, whereas only $9.5 \pm$ $2 \%$ of all $\mathrm{DAF}^{+}$cells were also $\mathrm{iNOS}^{+}$in the SC group. The difference between the number of $\mathrm{DAF}^{+} / \mathrm{iNOS}^{+}$cells in the SC and SD groups was statistically highly significant (Mann-Whitney rank sum test, $t=26.000, p=0.029)$. That $21.2 \pm 4 \%$ of all iNOS $^{+}$cells in the SD group did not show DAF-detected NO production suggested that immunolabeling was a slightly more sensitive measure than $\mathrm{DAF}^{+}$labeling. Of note, both measures showed a dramatic increase in numbers of positively labeled cells after SD, approximately fivefold for $\mathrm{DAF}^{+}$cells (Mann-Whitney rank sum test, $t=26.000, p=0.029$ ) and approximately eightfold for iNOS $^{+}$cells (Mann-Whitney rank sum test, $t=26.000$, $p=0.029$ ) (Fig. 5B).

The iNOS dependence of NO production during SD was further confirmed in iNOS KO mice and corresponding iNOS WT mice ( $6 \mathrm{~h} \mathrm{SD}, n=2$ per group) by repeating the same protocol as we used for rats. Similar to rats, there was abundant SD-induced $\mathrm{DAF}^{+} / \mathrm{iNOS}^{+}$staining in the BF of WT mice, but iNOS immunoreactivity was almost undetectable in the BF of iNOS KO mice and $\mathrm{DAF}^{+}$staining was significantly attenuated (Fig. 6).

\section{Double labeling shows that iNOS-dependent NO production} during SD occurs in neurons but not in glia

Although iNOS is primarily expressed in glial cells under most conditions (Calabrese et al., 2007), neuronal iNOS induction has been also reported in several studies (Heneka and Feinstein, 2001). To determine whether neurons and/or glia were responsible for SD-induced iNOS-dependent NO production, we performed double labeling of sections stained with DAF or iNOS antibody with antibodies specific for the neuronal marker NeuN or the glial marker GFAP (SD and SC conditions, $n=4$ animals for each of the 2 stain pairs). The iNOS $^{+}$staining in the SD group was colocalized with most of the $\mathrm{NeuN}^{+}$cells but not colocalized with GFAP ${ }^{+}$(Fig. 7 A, B). Only minimal, weak iNOS ${ }^{+}$staining in the $\mathrm{SC}$ group could be seen in glia and, to a lesser extent, in neurons. Similarly, $\mathrm{DAF}^{+}$ staining in SD group was primarily colocalized with NeuN but not GFAP (Fig. 7C,D). In SC animals, no $\mathrm{DAF}^{+}$staining was observed in glia, although some was observed in neurons, likely as a result of incomplete inhibition of nNOS, as described above.

SD-dependent iNOS induction in the BF occurs in prolonged wake-active neurons and positively correlates with homeostatic sleep pressure

Next, we sought to understand the functional identity of neurons expressing iNOS during SD. Because iNOS induction is known to be triggered by metabolic challenge (Moro et al., 1998), we speculated that iNOS induction might correlate with neuronal activation and be produced in cells active during prolonged wake. To test this hypothesis, we performed double labeling of iNOSstained sections from two groups of rats not treated with DAF2/DA and L-NPA (SD and SC conditions, $n=7$ per group) with antibody specific for Fos, the protein product of the immediateearly gene c-fos and a marker of neuronal activation (Morgan and Curran, 1986; Cirelli and Tononi, 2000).

We observed that SD induced an $\sim 10$-fold increase in the number of $\mathrm{Fos}^{+}$cells in the BF compared with SC (Mann-Whitney rank sum test, $t=77.000, p<0.001$ ) and an approximately eightfold increase in the total number of iNOS $^{+}$cells (MannWhitney rank sum test, $t=77.000, p<0.001)$. The majority of iNOS $^{+}$cells in SD group $(94.0 \pm 2 \%$ of total number $)$ were also $\mathrm{Fos}^{+}$. However, some Fos ${ }^{+}$cells were iNOS-negative $(15.0 \pm 3 \%$ of total number of $\mathrm{Fos}^{+}$cells), thus showing that not all prolonged wake-active cells expressed detectable iNOS during SD (Fig. $8 A, B)$. We compared the numbers of cells expressing iNOS $^{+} / \mathrm{Fos}^{+}$after $6 \mathrm{~h} \mathrm{SD}$ with those after $3 \mathrm{~h} \mathrm{SD}(n=4)$ and found that there was a significant increase after $6 \mathrm{~h} \mathrm{SD}$ (by $42 \%$, Mann-Whitney rank sum test, $t=10.500, p=0.006)$. Thus, SD induces progressive increase in $\mathrm{iNOS}^{+} / \mathrm{FOS}^{+}$cells in the $\mathrm{BF}$, suggesting that their number might correlate with homeostatic sleep pressure. 
To determine whether iNOS induction in prolonged wake-active neurons during SD was related to increased homeostatic sleep pressure, we examined the number of attempts to enter NREM sleep from wake during the last $2 \mathrm{~h}$ of $6 \mathrm{~h}$ SD before decapitation, as described in Materials and Methods. We found that the number of $\mathrm{iNOS}^{+} / \mathrm{Fos}^{+}$cells was strongly and positively correlated with attempts to enter sleep (Pearson's $r=0.889, p=$ 0.00745) (Fig. 8C).

SD-dependent iNOS induction in the BF is not triggered by stress: absence of increase in $\mathrm{Fos}^{+}$staining in stressassociated brain regions and plasma corticosterone level in sleep-deprived animals

Our study sought to minimize any possible stress from SD and other procedures by habituating animals to the experimenter, cage, and connection to the recording cable before experiments began, as described in Materials and Methods. Nonetheless, we considered it important to rule out the possibility that BF iNOS induction was not the result of stress associated with gentle handling SD procedures but rather the result of the prolongation of wakefulness. We thus examined for Fos ${ }^{+}$ staining in $\mathrm{PVH}$ and $\mathrm{CeA}$, regions found to have Fos induction during stressful stimuli (Cano et al., 2008) in the same SD and SC rats ( $n=4$ per group) used for iNOS ${ }^{+} / \mathrm{Fos}^{+}$immunolabeling in the BF. We also included four additional rats that were killed at 1:00 A.M. (6 h WC group). There was no increase in $\mathrm{Fos}^{+}$cells in SD group compared with SC or WC in either PVH (Kruskal-Wallis one-way ANOVA on ranks, $H_{(2)}=1.077, p=$ 0.630 ) or CeA (Kruskal-Wallis one-way ANOVA on ranks, $H_{(2)}$ $=0.151, p=0.941)($ Fig. $9 A-C)$. Because induction of iNOS in the brain can also indicate stress (Olivenza et al., 2000), we examined PVH and CeA for the presence of $\mathrm{iNOS}^{+}$staining and found that there was virtually no iNOS ${ }^{+}$or Fos $^{+} / \mathrm{iNOS}^{+}$ double staining in either the SC group or the SD group. This suggests that the conjoint $\mathrm{iNOS}^{+} / \mathrm{Fos}^{+}$expression in the $\mathrm{BF}$ observed by us was not the result of stress.

To further evaluate for stress effects, we also examined the changes in the humoral stress factor plasma corticosterone. We compared the levels of plasma corticosterone in the same 12 rats from SD, SC, and WC groups ( $n=4$ per group) and found no significant difference between groups (Kruskal-Wallis one-way ANOVA on ranks, $H_{(2)}=1.385, p=0.557$ ) (Fig. 9D). Finally, we found no correlation between the level of corticosterone and $\mathrm{iNOS}^{+} / \mathrm{Fos}^{+}$induction in the BF in SD and SC groups (Pearson's $r=-0.0636, p=0.881$ ).

\section{Discussion}

Our findings that SD-induced iNOS expression and NO production occur in neurons and after neuronal activation have not, to our knowledge, been reported previously. During SD, iNOS expression is increased by approximately sevenfold and is associated with an approximately fourfold increase in NO production,
B
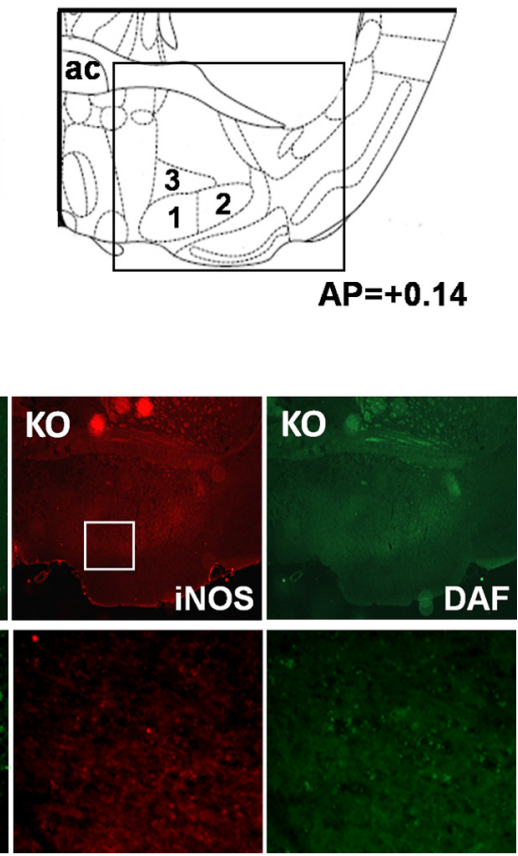

Figure 6. The absence of SD-induced iNOS and NO production in the iNOS knock-out mouse. iNOS KO mouse and corresponding were intracerebroventricularly infused in vivo with DAF-2/DA and L-NPA during SD (see Materials and Methods). $\boldsymbol{A}$, Position of ventricle $B$. Rectangle indicates the location of the area shown in photomicrographs in $C$. Anterior commissure 1, HDB. 2 MCPO; 3, SI. C, SD-induced iNOS ${ }^{+}$(red) and DAF ${ }^{+}$(green) stains were detected in the WT but in not in the KO mouse. Areas shown by rectangles in the top panels are magnified in bottom panels. Scale bars, $100 \mu \mathrm{m}$.

as detected by our novel in vivo method involving intracerebroventricular infusion of DAF-2/DA. That NO is produced by iNOS as indicated by their strong colocalization; $92 \%$ of cells that produce $\mathrm{NO}$ after SD are $\mathrm{iNOS}^{+}$. Moreover, the SDinduced iNOS expression occurs in prolonged wake-active neurons, as indicated by the presence of Fos immunoreactivity in $94 \%$ of iNOS $^{+}$cells. The number of $\mathrm{iNOS}^{+} / \mathrm{Fos}^{+}$cells correlates with sleep pressure during SD, which was measured by the number of attempts to enter sleep. Finally, our data indicate that the SD-induced increase in iNOS is not attributable to a stress response associated with SD.

Much of the literature has considered brain iNOS-dependent NO production as mainly occurring in glia, microglia, and astrocytes in response to pathological processes, including those during infection, brain trauma, stroke, hypoxia, and stress, as well as neurodegenerative diseases, such as multiple sclerosis and Alzheimer's and Parkinson's diseases (Zhan et al., 2005; Saha and Pahan, 2006; Calabrese et al., 2007). However, several recent studies have demonstrated that iNOS can be also induced in neurons (Heneka and Feinstein, 2001; Small et al., 2004). Similar to glial iNOS induction, neuronal iNOS induction has been shown to occur after stimulation by proinflammatory mediators, including lipopolysaccharide (LPS) or an LPS/interferon- $\gamma$ combination (Combs et al., 2001; Small et al., 2004). Moreover, induction of neuronal iNOS occurs in metabolically challenging conditions of hypoxia and hypoglycemia (Moro et al., 1998; Heneka and Feinstein, 2001). Unlike glial induction, neuronal iNOS induction alone does not lead to cell death (Combs et al., 2001; Small et al., 2004), thus suggesting that appearance of 

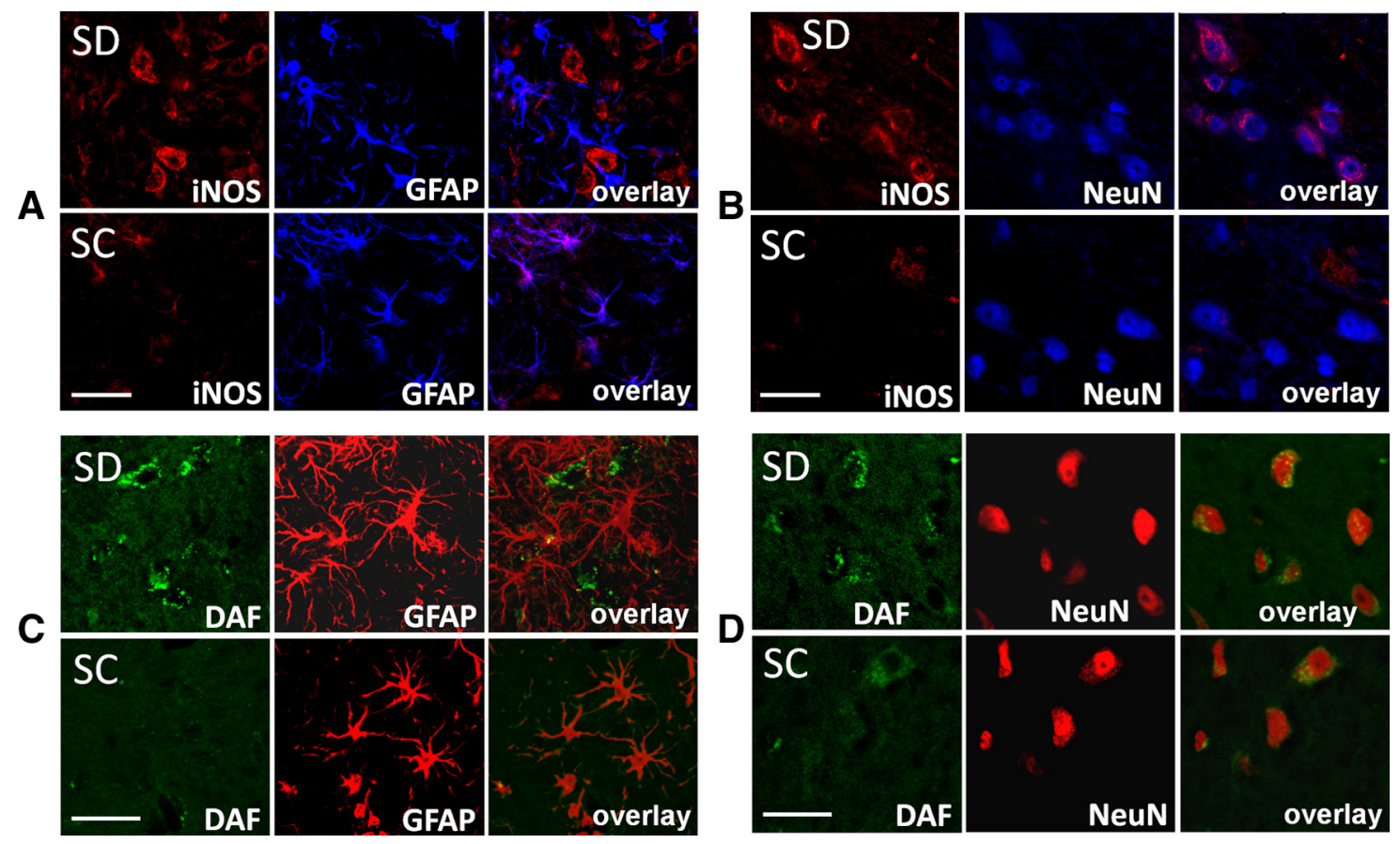

Figure 7. Double labeling of iNOS- or DAF-stained section with glial marker GFAP and neuronal marker NeuN. Sections stained for iNOS $(A, B)$ or DAF $(C, D)$ from the BF of rats in SD and SC groups doubled labeled for either GFAP or NeuN. Rightmost frame is merged image in all panels. $A$, No colocalization between iNOS ${ }^{+}$(red) and GFAP ${ }^{+}$(blue) is detected in SD group. In SC group, the weak iNOS ${ }^{+}$staining is only rarely colocalized with $\mathrm{GFAP}^{+}$. B, In SD group, the majority of iNOS ${ }^{+}$cells (red) are NeuN ${ }^{+}$(blue), whereas in SC group, the weak iNOS staining is only rarely colocalized with NeuN. C, No colocalization between $\mathrm{DAF}^{+}$(green) and GFAP ${ }^{+}$(red) is detected in either the SD or SC group. $\mathbf{D}, \mathrm{InSD}_{\text {group, the majority of DAF }}{ }^{+}$cells are NeuN ${ }^{+}$. Overall in the SC group, only a few neurons were NeuN ${ }^{+} / \mathrm{DAF}{ }^{+}$; one neuron in this section is double labeled. Presence of $\mathrm{N} 0$ in neurons in SC group likely resulted from incomplete inhibition of nNOS (see Fig. 4). Scale bars, $50 \mu \mathrm{m}$.

A

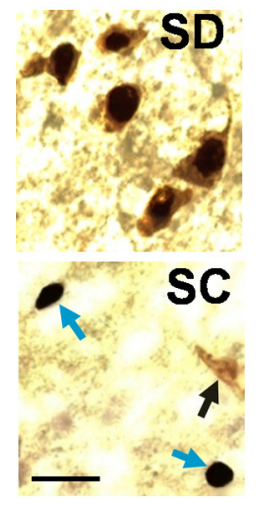

B

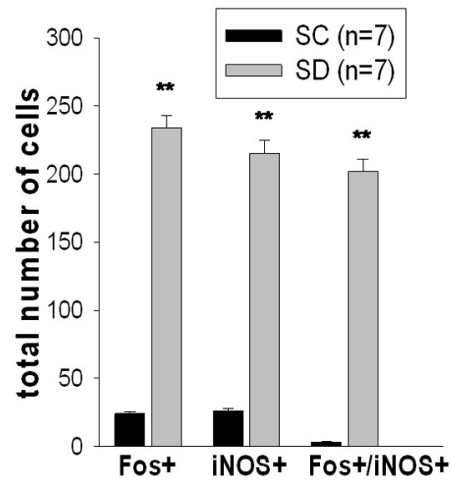

C

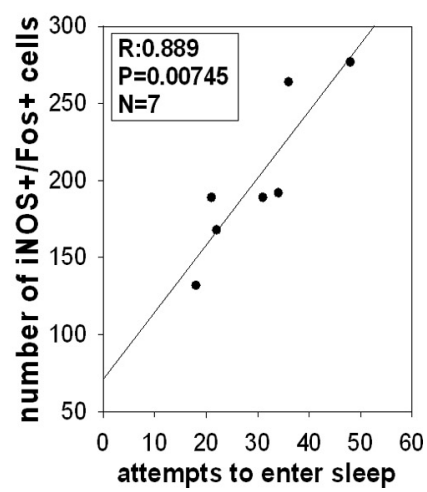

Figure 8. Double labeling of iNOS-stained sections with Fos, a marker of neuronal activation. $A$, Photomicrographs of the BF sections stained for iNOS and Fos. In this representative slide from the SD group, all shown iNOS ${ }^{+}$cells are also Fos ${ }^{+}$. In the SC representative section, weak iNOS (shown by black arrows) and Fos (shown by blue arrows) stainings are not colocalized. $\boldsymbol{B}$, Quantitative analysis of the numbers of iNOS ${ }^{+}, \mathrm{Fos}^{+}$, and iNOS ${ }^{+} / \mathrm{Fos}^{+}$cells in SD and SC groups. Note that almost all of iNOS ${ }^{+}$ cells are also Fos ${ }^{+} .{ }^{* *} p<0.001$, SD significantly different from SC. C, Correlation between the numbers of iNOS ${ }^{+} / F_{0 s}{ }^{+}$cells in the SD group and attempts to enter into sleep during last $2 \mathrm{~h}$ of SD $(n=7)$. Note the strong positive correlation. Scale bar, $50 \mu \mathrm{m}$.

iNOS in neurons could be the part of neuroprotective rather than a neurodegenerative mechanism.

Our data and the literature raise the possibility that NO production is also a protective response, albeit to less severe metabolic challenge than hypoglycemia and hypoxia. It is known that a majority of BF neurons show tonically increased firing during wakefulness, functionally related to maintenance of cortical arousal and associated cognitive operations (Baxter and Chiba, 1999; Szymusiak et al., 2000; Jones, 2005; Lee et al., 2005). During $\mathrm{SD}, \mathrm{BF}$ neuronal activity is increased even more than in spontaneous wakefulness, as shown by the degree of Fos immunoreactiv- ity (Greco et al., 2000; Modirrousta et al., 2004; McKenna et al., 2009). A positive correlation between the number of $\mathrm{iNOS}^{+} /$ $\mathrm{Fos}^{+}$cells in BF and homeostatic sleep pressure (Fig. 8) suggests that the Fos expression in BF serves as an index of sleep need. We note further that a sleep pressureassociated increase in Fos immunoreactivity has been reported previously in response to $6 \mathrm{~h}$ and longer durations of SD in other sleep-related areas, such as paraventricular thalamus (Semba et al., 2001) and medial preoptic area (Cirelli et al., 1995). One of the major factors contributing to increased Fos expression, despite the increased NO- and adenosine-induced inhibitory effects on BF neurons, may be excitatory input from brainstem, both from glutamatergic reticular formation neurons and noradrenergic locus ceruleus neurons, neurons activated during SD procedures (for review, see Jones, 2003; Steriade and McCarley, 2005).

Prolonged wakefulness is likely metabolically challenging for the BF wake-active cells, because continuous activation of neurons is known to increase their energy demands (Wong-Riley, 1989). Our present data thus are compatible with the possibility that iNOS induction during SD could also be functionally related to a protective response to $\mathrm{SD}$-associated energy expenditure and metabolic challenge.

The relationship of $\mathrm{NO}$ and adenosine adds support to this hypothesis. Our in vivo results indicate that NO donors act to induce sleep through adenosine production (Kalinchuk et al., 2006a). Moreover, preliminary in vitro evidence indicates that 
$\mathrm{NO}$ acts to produce adenosine-mediated neuronal hyperpolarization and inhibition (Franciosi et al., 2008). The NO-adenosine relationship is consistent with a large literature on the neuroprotective effects of adenosine (Basheer et al., 2004), which acts to decrease the level of energy expenditure via decreased neuronal activation (Dunwiddie and Masino, 2001; Cunha, 2005). Evidence of the action of adenosine to inhibit wake-active neurons is particularly strong in the BF: adenosine postsynaptically inhibits wake-active $\mathrm{BF}$ neurons via the $A_{1}$ receptor (Thakkar et al., 2003a; Arrigoni et al., 2006), pharmacologically increasing adenosine in the BF decreases wakefulness (PorkkaHeiskanen et al., 1997; Basheer et al., 1999), and antisense to the $A_{1}$ receptor and $\mathrm{A}_{1}$ antagonist strongly blunt recovery sleep (Thakkar et al., 2003b; Gass et al., 2009). NO action to produce adenosine may result from inhibition of adenosine kinase, the enzyme that converts adenosine to AMP (Rosenberg et al., 2000) and/or by decreasing ATP production by actions on the electron-transport chain and mitochondrial respiration (Brorson et al., 1999). It is unclear whether adenosine is released from the same neurons in which NO is produced or from the neighboring cells, because NO is a highly diffusible molecule (Calabrese et al., 2007). Previous data, including our own, indicated that SD-induced adenosine release is impaired after the lesion of BF cholinergic neurons (Blanco-Centurion et al., 2006; Kalinchuk et al., 2008). Conversely, other data indicate the important, and possibly leading, role of the astrocytes in adenosine release (Halassa et al., 2009).

That increased iNOS or DAF labeling is visible only in sleep-deprived animals and not during spontaneous waking is compatible with the iNOS-dependent NO response being part of a homeostatic cascade of responses to prolonged waking, with the initial level of response being increased BF adenosine (seen in spontaneous waking), followed by an iNOS/NO increase during longer-duration, forced wakefulness. It is possible that the sustained, increased excitatory input from brainstem to BF elicited in the course of SD may be responsible for iNOS induction in wake-active cells during SD.

After spontaneous wakefulness, when increased adenosinergic tone leads to inhibition of wake-active cells and decreases neuronal activation, iNOS is not induced. It is also possible that a very low iNOS/NO response occurs with spontaneous waking and is not detectable by our methods. A previous study showed that iNOS KO mice had less NREM sleep during the dark period (Chen et al., 2003). However, our study showed that infusion of an iNOS-selective inhibitor into BF did not affect spontaneous

\section{B Number of Fos+ cells in PVH}

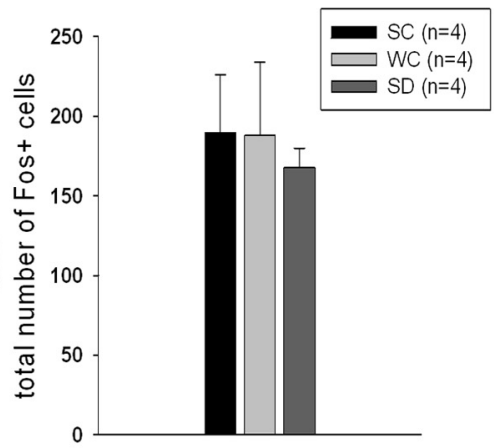

C Number of Fost cells in $\mathrm{CeA}$
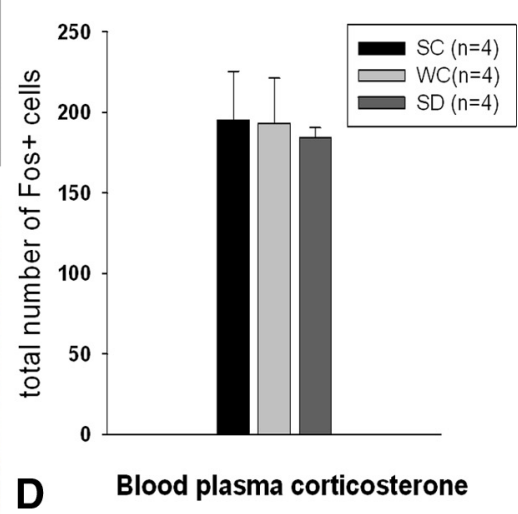

Figure 9. SD does not induce increases in Fos expression in central amygdala and paraventricular hypothalamus, key components of the stress network, and does not elevate blood plasma corticosterone level. $A$, Top panels show the location of the areas in photomicrographs (bottom panels) in the PVH and CeA. Middle panels show the areas indicated by squares in top panels. BLA Basolateral amygdaloid nucleus, anterior part; BLP, basolateral amygdaloid nucleus, posterior part; CeC, central amygdaloid nucleus, capsular part; CeL, central amygdaloid nucleus, lateral division; CeM, central amygdaloid nucleus, medial division; PaDC, paraventricular hypothalamic nucleus, dorsal cap; PaLM, paraventricular hypothalamic nucleus, lateral magnocellular part; PaMP, paraventricular hypothalamic nucleus, medial parvicellular part; PaV, paraventricular hypothalamic nucleus, ventral part. $\boldsymbol{B}, \boldsymbol{C}$ Note that the numbers of Fos ${ }^{+}$cells did not vary between SC, WC, and SD groups. Quantitative analysis of Fos ${ }^{+}$cells did not reveal any difference between SD, SC, and WC groups in PVH (B) and CeA (C). D, The level of blood plasma corticosterone did not increase in SD group compared with SC and WC. Scale bars, $200 \mu \mathrm{m}$.

sleep during light period (Kalinchuk et al., 2006b). We note that the increased level of adenosine response to SD is considerably higher than the modest increases during spontaneous wake in cats and rats (Porkka-Heiskanen et al., 1997; McKenna et al., 2003; Murillo-Rodriguez et al., 2004), and it is possible that a similar response gradient is present for iNOS/NO but not detectable at the levels occurring during spontaneous wake.

Because the NO response is detected only with SD, the absence of an SD stress-related response in our data is important. Often, brain iNOS induction, mostly in the cortex, has been associated with stressful stimuli (Olivenza et al., 2000; Calabrese et al., 
2007). Moreover, concerns have been expressed over forced wakefulness during SD being a stressful state (Semba et al., 2001). Almost all forms of SD, including wheel rotation, gentle handling, and the platform method, might involve some form of stress resulting from the novelty of the manipulations (Meerlo et al., 2002; Mashoodh et al., 2008). Gentle handling is generally considered to be the least stressful SD approach (Rechtschaffen et al., 1999), although not all agree (Semba et al., 2001). Nonetheless, our study considered it important to rule out the possibility that BF iNOS induction was not the result of stress associated with gentle handling SD. We thus examined two brain areas shown previously to be associated with stress-induced Fos induction during cage exchange with another rat ( $\mathrm{PVH}$ and $\mathrm{CeA})$ (Cano et al., 2008) and observed the absence of increase in Fos ${ }^{+}$ staining after SD compared with SC or WC and complete absence of $\mathrm{iNOS}^{+}$and $\mathrm{iNOS}^{+} / \mathrm{Fos}^{+}$double staining in the same rats that had increase in NOS $^{+} / \mathrm{Fos}^{+}$staining in the BF. In the same animals used for these Fos studies, we compared the level of plasma corticosterone and found no difference between sleepdeprived and control groups. This is in agreement with the previously published observation that $\mathrm{SD}$ induced by forced locomotion does not induce the activation of hypothalamopituitary-adrenal stress response (Tobler et al., 1983; Tartar et al., 2009).

In summary, we view $\mathrm{NO}$ production via iNOS induction in $\mathrm{BF}$ neurons as part of the homeostatic cascade of responses to sleep loss. This model of an iNOS-induced homeostatic, compensatory mechanism would place SD-induced iNOS as yet another example of phylogenetically ancient defense and compensatory iNOS-based mechanisms, with inciting events and responses that range from starvation and sporulation in macroplasmodia (Golderer et al., 2001) to bacterial infection and responses in teleost fish (CamposPerez et al., 2000) and mammals (Bogdan et al., 2000).

\section{References}

Arrigoni E, Chamberlin NL, Saper CB, McCarley RW (2006) Adenosine inhibits basal forebrain cholinergic and noncholinergic neurons in vitro. Neuroscience 140:403-413.

Basheer R, Porkka-Heiskanen T, Stenberg D, McCarley RW (1999) Adenosine and behavioral state control: adenosine increases c-Fos protein and AP1 binding in basal forebrain of rats. Mol Brain Res 73:1-10.

Basheer R, Strecker RE, Thakkar MM, McCarley RW (2004) Adenosine and sleep-wake regulation. Prog Neurobiol 73:379-396.

Basheer R, Bauer A, Elmenhorst D, Ramesh V, McCarley RW (2007) Sleep deprivation upregulates $\mathrm{Al}$ adenosine receptors in the rat basal forebrain. Neuroreport 18:1895-1899.

Baxter MG, Chiba AA (1999) Cognitive functions of the basal forebrain. Curr Opin Neurobiol 9:178-183.

Blanco-Centurion C, Xu M, Murillo-Rodriguez E, Gerashchenko D, Shiromani AM, Salin-Pascual RJ, Hof PR, Shiromani PJ (2006) Adenosine and sleep homeostasis in the basal forebrain. J Neurosci 26:8092-8100.

Bogdan C, Röllinghoff M, Diefenbach A (2000) The role of nitric oxide in innate immunity. Immunol Rev 173:17-26.

Borbély AA (1982) A two process model of sleep regulation. Hum Neurobiol 1:195-204.

Bredt DS, Snyder SH (1989) Nitric oxide mediates glutamate-linked enhancement of cGMP levels in the cerebellum. Proc Natl Acad Sci U S A 86:9030-9033.

Brorson JR, Schumacker PT, Zhang H (1999) Nitric oxide acutely inhibits neuronal energy production. The Committees on Neurobiology and Cell Physiology. J Neurosci 19:147-158.

Burlet S, Leger L, Cespuglio R (1999) Nitric oxide and sleep in the rat: a puzzling relationship. Neuroscience 92:627-639.

Calabrese V, Mancuso C, Calvani M, Rizzarelli E, Butterfield DA, Stella AM (2007) Nitric oxide in the central nervous system: neuroprotection versus neurotoxicity. Nat Rev Neurosci 8:766-775.

Campos-Perez JJ, Ward M, Grabowski PS, Ellis AE, Secombes CJ (2000)
The gills are an important site of iNOS expression in rainbow trout Oncorhynchus mykiss after challenge with the gram-positive pathogen Renibacterium salmoninarum. Immunology 99:153-161.

Cano G, Mochizuki T, Saper CB (2008) Neural circuitry of stress-induced insomnia in rats. J Neurosci 28:10167-10184.

Chen L, Majde JA, Krueger JM (2003) Spontaneous sleep in mice with targeted disruption of neuronal or inducible nitric oxide synthase genes. Brain Res 973:214-222.

Cirelli C, Tononi G (2000) On the functional significance of $c$-fos induction during the sleep-waking cycle. Sleep 23:453-469.

Cirelli C, Pompeiano M, Tononi G (1995) Sleep deprivation and $c$-fos expression in the rat brain. J Sleep Res 4:92-106.

Combs CK, Karlo JC, Kao SC, Landreth GE (2001) $\beta$-Amyloid stimulation of microglia and monocytes results in TNF $\alpha$-dependent expression of inducible nitric oxide synthase and neuronal apoptosis. J Neurosci 21:1179-1188.

Cunha RA (2005) Neuroprotection by adenosine in the brain: from $A_{1}$ receptor activation to $\mathrm{A}_{2 \mathrm{~A}}$ receptor blockade. Purinergic Signal 1:111-134.

Dunwiddie TV, Masino SA (2001) The role and regulation of adenosine in the central nervous system. Annu Rev Neurosci 24:31-55.

Dzoljic E, van Leeuwen R, de Vries R, Dzoljic MR (1997) Vigilance and EEG power in rats: effects of potent inhibitors of the neuronal nitric oxide synthase. Naunyn Schmiedebergs Arch Pharmacol 356:56-61.

Dzoljic MR, De Vries R (1994) Nitric oxide synthase inhibition reduces wakefulness. Neuropharmacology 33:1505-1509.

Dzoljic MR, de Vries R, van Leeuwen R (1996) Sleep and nitric oxide: effects of 7-nitro indazole, inhibitor of brain nitric oxide synthase. Brain Res 718:145-150.

Elmenhorst D, Meyer PT, Winz OH, Matusch A, Ermert J, Coenen HH, Basheer R, Haas HL, Zilles K, Bauer A (2007) Sleep deprivation increases $A_{1}$ adenosine receptor binding in the human brain: a positron emission tomography study. J Neurosci 27:2410-2415.

Elmenhorst D, Basheer R, McCarley RW, Bauer A (2009) Sleep deprivation increases $A_{1}$ adenosine receptor density in the rat brain. Brain Res 1258:53-58.

Franciosi S, Yanagawa Y, McCarley RW, Brown R (2008) The putative sleep homeostatic factor adenosine selectively inhibits one type of basal forebrain GABA neurons. Sleep 31 [Abstr Suppl]: A14.

Franken P, Dijk DJ, Tobler I, Borbély AA (1991) Sleep deprivation in rats: effects on EEG power spectra, vigilance states, and cortical temperature. Am J Physiol 261:R198-R208.

Franklin KBJ, Paxinos G (2007) The mouse brain in stereotaxic coordinates. San Diego: Academic.

Gass N, Porkka-Heiskanen T, Kalinchuk AV (2009) The role of the basal forebrain adenosine receptors in sleep homeostasis. Neuroreport 20:1013-1018.

Golderer G, Werner ER, Leitner S, Gröbner P, Werner-Felmayer G (2001) Nitric oxide synthase is induced in sporulation of Physarum polycephalum. Genes Dev 15:1299-1309.

Greco MA, Lu J, Wagner D, Shiromani PJ (2000) c-Fos expression in the cholinergic basal forebrain after enforced wakefulness and recovery sleep. Neuroreport 11:437-440.

Halassa MM, Florian C, Fellin T, Munoz JR, Lee SY, Abel T, Haydon PG, Frank MG (2009) Astrocytic modulation of sleep homeostasis and cognitive consequences of sleep loss. Neuron 61:213-219.

Heneka MT, Feinstein DL (2001) Expression and function of inducible nitric oxide synthase in neurons. J Neuroimmunol 114:8-18.

Jones BE (2003) Arousal systems. Front Biosci 8:438-451.

Jones BE (2005) From waking to sleeping: neuronal and chemical substrates. Trends Pharmacol Sci 26:578-586.

Kalinchuk AV, Lu Y, Stenberg D, Rosenberg PA, Porkka-Heiskanen T (2006a) Nitric oxide production in the basal forebrain is required for recovery sleep. J Neurochem 99:483-498.

Kalinchuk AV, Stenberg D, Rosenberg PA, Porkka-Heiskanen T (2006b) Inducible and neuronal nitric oxide synthases (NOS) have complementary roles in recovery sleep induction. Eur J Neurosci 24:1443-1456.

Kalinchuk AV, McCarley RW, Stenberg D, Porkka-Heiskanen T, Basheer R (2008) The role of cholinergic basal forebrain neurons in adenosinemediated homeostatic control of sleep: lessons from 192 IgG-saporin lesions. Neuroscience 157:238-253.

Kapás L, Krueger JM (1996) Nitric oxide donors SIN-1 and SNAP promote nonrapid-eye-movement sleep in rats. Brain Res Bull 41:293-298. 
Kapás L, Shibata M, Kimura M, Krueger JM (1994a) Inhibition of nitric oxide synthesis suppresses sleep in rabbits. Am J Physiol 266:R151-R157.

Kapás L, Fang J, Krueger JM (1994b) Inhibition of nitric oxide synthesis inhibits rat sleep. Brain Res 664:189-196.

Kojima H, Nakatsubo N, Kikuchi K, Kawahara S, Kirino Y, Nagoshi H, Hirata Y, Nagano T (1998a) Detection and imaging of nitric oxide with novel fluorescent indicators: diaminofluoresceins. Anal Chem 70:2446-2453.

Kojima H, Nakatsubo N, Kikuchi K, Urano Y, Higuchi T, Tanaka J, Kudo Y, Nagano T (1998b) Direct evidence of NO production in rat hippocampus and cortex using a new fluorescent indicator: DAF-2 DA. Neuroreport 9:3345-3348.

Lee MG, Hassani OK, Alonso A, Jones BE (2005) Cholinergic basal forebrain neurons burst with theta during waking and paradoxical sleep. J Neurosci 25:4365-4369.

Mashoodh R, Stamp JA, Wilkinson M, Rusak B, Semba K (2008) Lack of estradiol modulation of sleep deprivation-induced c-Fos in the rat brain. Physiol Behav 95:562-569.

McCarley RW (2007) Neurobiology of REM and NREM sleep. Sleep Med 8:302-330.

McKenna JT, Dauphin LJ, Mulkern KJ, Stronge AM, McCarley RE, Strecker RE (2003) Nocturnal elevation of extracellular adenosine in the rat basal forebrain. Sleep Res Online 5:155-160.

McKenna JT, Cordeira JW, Jeffrey BA, Ward CP, Winston S, McCarley RW, Strecker RE (2009) c-Fos protein expression is increased in cholinergic neurons of the rodent basal forebrain during spontaneous and induced wakefulness. Brain Res Bull 80:382-388.

Meerlo P, Koehl M, van der Borght K, Turek FW (2002) Sleep restriction alters the hypothalamic-pituitary-adrenal response to stress. J Neuroendocrinol 14:397-402.

Modirrousta M, Mainville L, Jones BE (2004) Gabaergic neurons with alpha2-adrenergic receptors in basal forebrain and preoptic area express c-Fos during sleep. Neuroscience 129:803-810.

Monti JM, Jantos H (2004) Microinjection of the nitric oxide synthase inhibitor L-NAME into the lateral basal forebrain alters the sleep/wake cycle of the rat. Prog Neuropsychopharmacol Biol Psychiatry 28:239-247.

Monti JM, Hantos H, Ponzoni A, Monti D, Banchero P (1999) Role of nitric oxide in sleep regulation: effects of L-NAME, an inhibitor of nitric oxide synthase, on sleep in rats. Behav Brain Res 100:197-205.

Morgan JI, Curran T (1986) Role of ion flux in the control of c-fos expression. Nature 322:552-555.

Moro MA, De Alba J, Leza JC, Lorenzo P, Fernández AP, Bentura ML, Boscá L, Rodrigo J, Lizasoain I (1998) Neuronal expression of inducible nitric oxide synthase after oxygen and glucose deprivation in rat forebrain slices. Eur J Neurosci 10:445-456.

Murillo-Rodriguez E, Blanco-Centurion C, Gerashchenko D, Salin-Pascual RJ, Shiromani PJ (2004) The diurnal rhythm of adenosine levels in the basal forebrain of young and old rats. Neuroscience 123:361-370.

Olivenza R, Moro MA, Lizasoain I, Lorenzo P, Fernández AP, Rodrigo J, Boscá L, Leza JC (2000) Chronic stress induces the expression of inducible nitric oxide synthase in rat brain cortex. J Neurochem 74:785-791.

Paxinos G, Watson C (1998) The rat brain in stereotaxic coordinates. San Diego: Academic.
Porkka-Heiskanen T, Strecker RE, Thakkar M, Bjorkum AA, Greene RW, McCarley RW (1997) Adenosine: a mediator of the sleep-inducing effects of prolonged wakefulness. Science 276:1265-1268.

Porkka-Heiskanen T, Strecker RE, McCarley RW (2000) Brain sitespecificity of extracellular adenosine concentration changes during sleep deprivation and spontaneous sleep: an in vivo microdialysis study. Neuroscience 99:507-517.

Rechtschaffen A, Bergmann BM, Gilliland MA, Bauer K (1999) Effects of method, duration, and sleep stage on rebounds from sleep deprivation in the rat. Sleep 22:11-31.

Rosenberg PA, Li Y, Le M, Zhang Y (2000) Nitric oxide-stimulated increase in extracellular adenosine accumulation in rat forebrain neurons in culture is associated with ATP hydrolysis and inhibition of adenosine kinase activity. J Neurosci 20:6294-6301.

Saha RN, Pahan K (2006) Signals for the induction of nitric oxide synthase in astrocytes. Neurochem Int 49:154-163.

Semba K, Pastorius J, Wilkinson M, Rusak B (2001) Sleep deprivationinduced c-fos and junB expression in the rat brain: effects of duration and timing. Behav Brain Res 120:75-86.

Small CI, Lyles GA, Breen KC (2004) Inducible form of nitric oxide synthase expression in rat cortical neuronal cells in vitro. Neurobiol Dis 17:70-76.

Steriade M, McCarley RW (2005) Brain control of wakefulness and sleep. New York: Kluwer Academic.

Szymusiak R, Alam N, McGinty D (2000) Discharge patterns of neurons in cholinergic regions of the basal forebrain during waking and sleep. Behav Brain Res 115:171-182.

Tartar JL, Ward CP, Cordeira JW, Legare SL, Blanchette AJ, McCarley RW, Strecker RE (2009) Experimental sleep fragmentation and sleep deprivation increases exploration in an open field test of anxiety while increasing plasma corticosterone level. Behav Brain Res 197:450-453.

Thakkar MM, Delgiacco RA, Strecker RE, McCarley RW (2003a) Adenosinergic inhibition of basal forebrain wakefulness-active neurons: a simultaneous unit recording and microdialysis study in freely behaving cats. J Neurosci 122:1107-1113.

Thakkar MM, Winston S, McCarley RW (2003b) A1 receptor and adenosinergic homeostatic regulation of sleep-wakefulness: effects of antisense to the A1 receptor in the cholinergic basal forebrain. J Neurosci 23:4278-4287.

Tobler I, Murison R, Ursin R, Ursin H, Borbély AA (1983) The effect of sleep deprivation and recovery sleep on plasma corticosterone in the rat. Neurosci Lett 35:297-300.

Williams JA, Vincent SR, Reiner PB (1997) Nitric oxide production in rat thalamus changes with behavioral state, local depolarization, and brainstem stimulation. J Neurosci 17:420-427.

Wong-Riley MT (1989) Cytochrome oxidase: an endogenous metabolic marker for neuronal activity. Trends Neurosci 12:94-101.

Zhan G, Fenik P, Pratico D, Veasey SC (2005) Inducible nitric oxide synthase in long-term intermittent hypoxia: hypersomnolence and brain injury. Am J Respir Crit Care Med 171:1414-1420.

Zhang HQ, Fast W, Marletta MA, Martasek P, Silverman RB (1997) Potent and selective inhibition of neuronal nitric oxide synthase by $\mathrm{N}$ omegapropyl-L-arginine. J Med Chem 40:3869-3870. 